\title{
Differential associations of angiographic extent and severity of coronary artery disease with asymmetric dimethylarginine but not insulin resistance in non-diabetic men with stable angina: a cross-sectional study
}

Olga Kruszelnicka ${ }^{1 *}$, Andrzej Surdacki ${ }^{2}$ and Alain Golay ${ }^{3}$

\begin{abstract}
Background: Asymmetric dimethylarginine (ADMA), an endogenous nitric oxide synthesis inhibitor, and insulin resistance $(I R)$ have been implicated in atherogenesis. Our aim was to estimate relations between ADMA, the magnitude of IR and angiographic indices of extent and severity of coronary atherosclerosis in non-diabetic men with stable coronary artery disease (CAD).
\end{abstract}

Methods: We studied 151 non-diabetic men (mean age $57 \pm 11$ years) with stable angina, obstructive CAD (at least 1 luminal diameter stenosis of $\geq 70 \%$ in major coronary segments) and without heart failure, and 34 age-matched controls free of $\geq 50 \%$ coronary narrowings. The following CAD indices were computed: the number of major epicardial vessels with $\geq 70 \%$ stenosis, Sullivan extent score representing a proportion of the visible coronary tree with vessel wall irregularities, and Gensini score which reflects both CAD severity and extent, yet assigning a heavier weight to proximal segments and to the more severe narrowings by a non-linear point system. An estimate of IR was derived by homeostasis model assessment (HOMA-IR) from fasting insulin and glucose.

Results: Among the CAD patients, the proportions of subjects with 1-vessel, 2-vessel and 3-vessel CAD were 26\%, $25 \%$ and $49 \%$, respectively. ADMA levels were higher in patients with obstructive CAD compared to the controls ( $0.51 \pm 0.10$ vs. $0.46 \pm 0.09 \mathrm{mmol} / \mathrm{L}$ [SD], $P=0.01$ ), whereas HOMA-IR was similar (median, 3.2 [interquartile range: 2.4-4.9] vs. 2.9 [2.3-4.7], $P=0.2$ ). Within the CAD group, ADMA increased across ascending quartiles of Sullivan score (Spearman's rho $=0.23, P=0.004$ ), but not with Gensini score (rho $=0.12, P=0.15$ ) or the number of vessels involved (rho $=0.08, P=0.3$ ). ADMA correlated to log-transformed Sullivan score (Pearson's $r=0.21, P=0.008$ ), which was only slightly attenuated upon multivariate adjustment $(\beta=0.19 \pm 0.08$ [SEM], $P=0.015)$. HOMA-IR did not differ according to any measure of angiographic CAD ( $P \geq 0.2)$. ADMA and $\log (\mathrm{HOMA}-\mathrm{R}$ ) were mutually unrelated ( $r=0.07, P=0.4$ ).

Conclusions: ADMA is associated with diffuse but not focal coronary atherosclerosis in non-diabetic men with stable CAD irrespectively of the degree of IR. The independent relationship between ADMA and coronary atherosclerotic burden may contribute to the well-recognized prognostic effect of ADMA in CAD.

Keywords: ADMA, Coronary artery disease, Insulin resistance

\footnotetext{
* Correspondence: olga.kruszelnicka@onet.pl

${ }^{1}$ Department of Coronary Artery Disease, The John Paul II Hospital, 80

Prądnicka Street, Cracow 31-202, Poland

Full list of author information is available at the end of the article
} 


\section{Background}

Asymmetric dimethylarginine (ADMA) - an endogenous inhibitor of nitric oxide (NO) formation - has been implicated in atherogenesis [1,2]. Nevertheless, despite a bulk of evidence linking ADMA to subclinical carotid atherosclerosis [3-5] and adverse cardiovascular (CV) events [6-10], there are inconsistent reports on the association between ADMA and angiographic coronary artery disease (CAD). Admittedly, the seminal publication by Lu et al. [11] and some other studies [10,12,13] suggested independent relations between elevated ADMA and the presence or extent of angiographic CAD. However, according to the largest reports on ADMA levels in predominantly stable CAD, positive correlations between ADMA and angiographic CAD either were absent [14] or lost significance on multivariate adjustment $[8,9]$, in contrast to detrimental prognostic effects of ADMA on CV outcome $[8,9,14]$.

The magnitude of insulin resistance (IR) has been linked to the incidence of symptomatic CV disease and adverse outcome [15-19]. It is noteworthy that, using a mathematical model, Eddy et al. [20] recently estimated that IR was the most important single cause of symptomatic CAD being responsible for about $42 \%$ of myocardial infarctions. Nevertheless, like with ADMA, reports on the relationship of angiographic CAD with IR or its surrogate measure, fasting insulinemia, are discordant with negative findings obtained in larger study groups [21-29]. In addition, there are inconsistent reports on the association between IR and ADMA levels in various clinical settings [30-43].

To the best of our knowledge, exclusively two studies examined the relationship of angiographic CAD with both IR and ADMA. First, our group had previously described independent and additive effects of a hyperinsulinemic euglycemic clamp-derived index of IR and an increased ADMA to L-arginine ratio, but not ADMA, on the number of major coronary vessels with $>50 \%$ narrowings in 53 patients with stable angina and pre-diabetes [35]. Second, Isiklar et al. [41] have recently observed the lack of correlation between ADMA and Gensini score in 75 stable angina subjects, including 17 type 2 diabetics. Nevertheless, ADMA was unrelated to the degree of IR in the both cited studies [35,41].

Therefore, in order to differentiate between the effects of ADMA and IR on coronary atherosclerosis, we investigated mutual relations between plasma ADMA, the degree of IR and angiographic indices of CAD extent and severity in non-diabetic men with stable CAD.

\section{Methods}

\section{Subjects}

We studied 151 non-diabetic men (mean age $57 \pm 11$ years) with stable CAD and significant epicardial coronary narrowings (at least 1 luminal diameter stenosis of $\geq 70 \%$ ) who underwent an elective coronary angiography. The current report has been based on the extension of the previously described group of $80 \mathrm{CAD}$ patients free of diabetes [43]. In addition, we recruited 34 control men (matched for age and body-mass index) among patients with suspected CAD who exhibited no coronary diameter narrowings $\geq 50 \%$.

Beyond diabetes (diagnosed according to the 2003 recommendations of the American Diabetes Association by either fasting glucose or postload glycemia during an oral glucose tolerance test as mentioned previously [43]), exclusion criteria - for the both groups - included heart failure, left ventricular systolic dysfunction (by ultrasound), congenital heart disease, significant valvular heart disease, acute coronary syndromes within previous 3 months, any surgery in past 6 months, infections within previous 2 months, arterial hypertension uncontrolled adequately by drugs, overt extracoronary atherosclerosis, relevant coexistent diseases, severely decreased estimated glomerular filtration rate (eGFR) $(<30 \mathrm{~mL} / \mathrm{min}$ per $1.73 \mathrm{~m}^{2}$ body-surface area according to the simplified equation developed by the Modification of Diet in Renal Disease study group [44]), other significant abnormalities in routine laboratory assays and any chronic non-CV medication as described earlier in detail $[43,45]$. Additionally, all the subjects were receiving an angiotensin-converting enzyme (ACE) inhibitor, statin and low-dose aspirin for $\geq 3$ months prior to index hospitalization $[43,45]$. In agreement with the Declaration of Helsinki, the protocol had been approved by the university ethics committee and each patient gave informed consent.

\section{Biochemical assays}

Peripheral venous blood sampling was performed $0-2$ days before elective coronary angiography, plasma was separated from ethylenediaminetetraacetic acid-anticoagulated blood and frozen at $-70^{\circ} \mathrm{C}$ until routine and extended biochemical assays. An index of IR was derived from homeostasis model assessment (HOMA-IR) as a product of fasting plasma insulin $(\mu \mathrm{U} / \mathrm{mL})$ and glucose $(\mathrm{mmol} / \mathrm{L})$ divided by 22.5 [46].

As described previously [43], plasma ADMA and Larginine were determined by a commercially available enzyme-linked immunosorbent assays (ELISA) (DLD Diagnostika GmbH., Hamburg, Germany), previously validated against high-performance liquid chromatography coupled to mass spectrometry, the golden standard for ADMA determinations [47]. According to the manufacturer, the lower detection limit of ADMA assay was $0.05 \mu \mathrm{mol} / \mathrm{L}$ and intra-assay and inter-assay coefficients of variation averaged 7.5 and $10.3 \%$, respectively. Cross-reactivity with L-arginine, symmetric 
dimethylarginine and $N^{G}$-monomethyl-L-arginine was $<0.02 \%, 1.2 \%$, and $1.0 \%$, respectively. With regard to Larginine, the lower detection limit was $3.0 \mu \mathrm{mol} / \mathrm{L}$, intra-assay and inter-assay coefficients of variation averaged $3.6 \%$ and $8.3 \%$, respectively, and cross-reactivity was $0.01 \%$ for ADMA and $0.68 \%$ for symmetric dimethylarginine.

\section{Angiographic indices of CAD}

Angiographic CAD was quantified by 3 different measures. First, we computed the number of vessels diseased, i.e., the number of major epicardial coronary arteries with $\geq 1$ luminal diameter stenosis of $\geq 70 \%$ ( $\geq 50 \%$ for the left main coronary artery considered 3 vessel disease in a left dominant circulation and equivalent to an additional two diseased vessels in a right dominant or balanced circulation) as developed by Ringqvist et al. [48] on the basis of the Coronary Artery Surgery Study (CASS). Second, according to Sullivan et al. [49], a CAD extent score was calculated representing an approximate proportional length of the visible coronary vessels with irregularities of the vessel wall [45]. In case of inadequate collateralization of totally occluded vessels, the mean extent score of the vessel segments proximal to the occlusion was assigned to the occluded segment. Third, we computed Gensini score which reflects both CAD extent and severity assigning a heavier weight to the more severe luminal narrowings (by a non-linear point system) and to coronary segments serving larger regions of the myocardium [50]. All angiographic analyses were performed by a cardiologist blinded to clinical and biochemical characteristics.

\section{Statistical analysis}

Data are shown as mean and SD for normally distributed continuous variables, median and interquartile range for not normally distributed values, and numbers with percentages for categorical characteristics. The accordance with a normal distribution was verified by the Lilliefors' test and logarithmic transformation was applied when necessary. Intergroup comparisons were performed by 2-sided unpaired Student's $t$-test or Fisher's exact test. Trend effects according to the number of vessels diseased or over the quartiles of Gensini and Sullivan scores were estimated by Spearman's rank-order correlation coefficient $(\rho)$ for continuous values and the chisquared test for trend for categorical data. Bivariate correlations were assessed by Pearson's correlation coefficient $(r)$. For multivariate approach, multiple linear regression was applied, including exclusively the covariates for which the univariate $P$ value was $\leq 0.15$.

Our study design allowed to detect a difference in mean ADMA concentrations and average HOMA-IR by $0.05 \mu \mathrm{mol} / \mathrm{L}$ and 0.8 , respectively (about $0.46 \mathrm{SD}$ ), between the CAD subjects with 3-vessel disease compared to those with 1-/2-vessel CAD with a statistical power of $80 \%$ at a type I error rate of 0.05 . Additionally, for the same power and type I error rate, bivariate correlations could be estimated with an $r$ value of 0.225 in the CAD group as a whole.

Analyses were performed using STATISTICA (data analysis software system, version 10.0.1011.0; StatSoft, Inc., Tulsa, OK, USA). A $P$ value $<0.05$ was inferred significant.

\section{Results}

Baseline patients' characteristics according to angiographic CAD

Intergroup comparisons are presented in Table 1. The presence of significant coronary narrowings was associated with a lower concentration of high-density lipoproteins (HDL) cholesterol, marginally reduced eGFR, and a tendency to higher high-sensitivity $\mathrm{C}$-reactive protein. In addition, ADMA levels were higher in patients with obstructive CAD compared to the controls $(0.51 \pm 0.10$ vs. $0.46 \pm 0.09 \mu \mathrm{mol} / \mathrm{L}, P=0.01)$, whereas HOMA-IR was similar across the groups (median 3.2 [2.4-4.9] vs. 2.9 [2.3-4.7], $P=0.2$ ) (Table 1 ).

Among the CAD patients, the proportions of subjects with 1-vessel, 2- vessel and 3-vessel CAD were 26\%, 25\% and $49 \%$, respectively. The median Sullivan score was 29 (20-41) and Gensini score 32 (15-64). Indices of CAD extent and severity were associated with an older age $(P=0.01-0.10)$, depressed eGFR $(P=0.008-0.02)$, lower HDL cholesterol $(P=0.0 .03-0.14)$ and a history of current smoking $(P=0.04-0.12)$.

\section{ADMA and HOMA-IR in relation to angiographic indices of CAD}

ADMA levels increased across ascending quartiles of Sullivan score $(\rho=0.23, P=0.004)$, but not with Gensini score $(\rho=0.12, P=0.15)$ or the number of vessels involved ( $\rho=0.08, P=0.3$ ) (Table 2 ). L-arginine levels did not differ between the subgroups irrespective of the criterion used for CAD quantification $(P>0.3)$.

ADMA correlated to log (Sullivan score) as a continuous variable $(r=0.21, P=0.008)$ (Figure 1$)$. By multiple linear regression with log-transformed Sullivan score as a dependent variable, the positive association of ADMA and $\log$ (Sullivan score) was only slightly attenuated upon adjustment for age, HDL cholesterol, eGFR and a history of current smoking (mean standardized $\beta: 0.19 \pm$ 0.08 [SEM], $P=0.015$; adjusted $R^{2}: 0.08, P<0.002$ ).

HOMA-IR did not differ significantly according to any measure of angiographic $\operatorname{CAD}(P \geq 0.2)$ (Table 2). ADMA and log-transformed HOMA-IR were unrelated $(r=0.07, P=0.4)$. 
Table 1 Baseline characteristics of CAD patients and controls

\begin{tabular}{|c|c|c|c|}
\hline Variable & CAD patients $(n=151)$ & Controls $(n=34)$ & $P$ value \\
\hline Age (years) & $57 \pm 11$ & $56 \pm 12$ & 0.6 \\
\hline Body-mass index $\left(\mathrm{kg} / \mathrm{m}^{2}\right)$ & $27.5 \pm 3.8$ & $27.3 \pm 3.7$ & 0.8 \\
\hline Current smokers, $n$ (\%) & $41(27 \%)$ & $7(21 \%)$ & 0.5 \\
\hline Left ventricular ejection fraction (\%) & $69 \pm 7$ & $70 \pm 6$ & 0.4 \\
\hline Hypertension, $n$ (\%) & $121(80 \%)$ & $25(74 \%)$ & 0.4 \\
\hline Systolic blood pressure $(\mathrm{mm} \mathrm{Hg})$ & $130 \pm 10$ & $129 \pm 12$ & 0.6 \\
\hline Diastolic blood pressure $(\mathrm{mm} \mathrm{Hg})$ & $79 \pm 8$ & $80 \pm 9$ & 0.5 \\
\hline Estimated GFR (mL/min per $\left.1.73 \mathrm{~m}^{2}\right)$ & $71 \pm 10$ & $75 \pm 13$ & 0.05 \\
\hline Low-density lipoproteins cholesterol (mmol/L) & $2.8 \pm 0.7$ & $2.6 \pm 0.7$ & 0.3 \\
\hline High-density lipoproteins cholesterol (mmol/L) & $0.9 \pm 0.3$ & $1.0 \pm 0.4$ & 0.02 \\
\hline Triglycerides (mmol/L) & $1.5 \pm 0.8$ & $1.4 \pm 0.7$ & 0.5 \\
\hline High-sensitivity C-reactive protein (mg/L) & $1.8(1.1-3.8)$ & $1.6(1.0-3.3)$ & 0.07 \\
\hline Glucose (mmol/L) & $5.8 \pm 0.8$ & $5.6 \pm 0.7$ & 0.25 \\
\hline HOMA-IR index & $3.2(2.4-4.9)$ & $2.9(2.3-4.7)$ & 0.2 \\
\hline ADMA $(\mu \mathrm{mol} / \mathrm{L})$ & $0.51 \pm 0.10$ & $0.46 \pm 0.09$ & 0.01 \\
\hline $\mathrm{L}$-arginine $(\mu \mathrm{mol} / \mathrm{L})$ & $70 \pm 18$ & $71 \pm 17$ & 0.7 \\
\hline
\end{tabular}

Data are shown as mean $\pm S D$, median (interquartile range) or $\mathrm{n}(\%)$.

Abbreviations: ADMA asymmetric dimethylarginine, CAD coronary artery disease, GFR glomerular filtration rate, HOMA-IR homeostasis model assessment for insulin resistance.

\section{Discussion}

Our salient finding was a rise in ADMA with increasing angiographic CAD extent but not with Gensini score or the number of major coronary vessels with a significant stenosis. Additionally, HOMA-IR was unrelated to either ADMA or any of the measures of angiographic CAD.

\section{ADMA versus angiographic $C A D$}

That ADMA concentrations were higher in those with angiographic obstructive CAD compared to the controls free of significant CAD, is consistent with 3 out of 5 largest reports on ADMA in relation to angiographic CAD [7-10,14].

Meinitzer et al. [8] reported a univariate, but not multivariate, association of ADMA with Friesinger score in 2,543 participants of the Ludwigshafen Risk and Cardiovascular Health (LURIC) study (60\% with stable CAD) with coronary stenoses $\geq 20 \%$, nevertheless, Friesinger score is more strongly influenced by the severity and number of coronary narrowings than by CAD extent [51]. Lu et al. [10] observed higher ADMA with increasing maximal stenosis ( $<20 \%$ vs. $20-49 \%$ vs. $\geq 50 \%)$ in major coronary arteries by both univariate and

Table 2 ADMA and HOMA-IR according to angiographic CAD indices

\begin{tabular}{|c|c|c|c|c|c|}
\hline & \multicolumn{3}{|c|}{ Number of vessels diseased } & & \\
\hline & 1-vessel CAD $(n=40)$ & 2-vessel CAD $(n=37)$ & 3-vessel CAD $(n=74)$ & \multicolumn{2}{|c|}{$P$ for trend } \\
\hline $\mathrm{ADMA}(\mu \mathrm{mol} / \mathrm{L})$ & $0.49 \pm 0.10$ & $0.52 \pm 0.11$ & $0.50 \pm 0.10$ & \multicolumn{2}{|c|}{0.3} \\
\hline HOMA-IR & $3.3(2.5-5.0)$ & $3.5(2.6-5.2)$ & $3.0(2.0-4.6)$ & & \\
\hline \multicolumn{6}{|c|}{ Sullivan extent score } \\
\hline & $1^{\text {st }}$ quartile $\leq 20$ & $2^{\text {nd }}$ quartile $21-29$ & $3^{\text {rd }}$ quartile $30-41$ & $4^{\text {th }}$ quartile $>41$ & $P$ for trend \\
\hline ADMA $(\mu \mathrm{mol} / \mathrm{L})$ & $0.48 \pm 0.09$ & $0.49 \pm 0.08$ & $0.52 \pm 0.10$ & $0.54 \pm 0.11$ & 0.004 \\
\hline HOMA-IR & $3.0(2.1-4.5)$ & $3.1(2.7-4.9)$ & $3.5(2.7-5.4)$ & $3.1(2.3-4.8)$ & 0.2 \\
\hline \multicolumn{6}{|c|}{ Gensini score } \\
\hline & $1^{\text {st }}$ quartile $<15$ & $2^{\text {nd }}$ quartile $15-32$ & $3^{\text {rd }}$ quartile $33-64$ & $4^{\text {th }}$ quartile $>64$ & $P$ for trend \\
\hline ADMA $(\mu \mathrm{mol} / \mathrm{L})$ & $0.49 \pm 0.10$ & $0.51 \pm 0.10$ & $0.50 \pm 0.11$ & $0.52 \pm 0.12$ & 0.15 \\
\hline HOMA-IR & $3.1(2.1-4.6)$ & $3.3(2.6-5.1)$ & $3.0(2.2-5.2)$ & $3.2(2.5-4.8)$ & 0.4 \\
\hline
\end{tabular}

Data are shown as mean \pm SD or median (interquartile range).

Abbreviations: ADMA asymmetric dimethylarginine, CAD coronary artery disease, GFR glomerular filtration rate, HOMA-IR homeostasis model assessment for insulin resistance. 


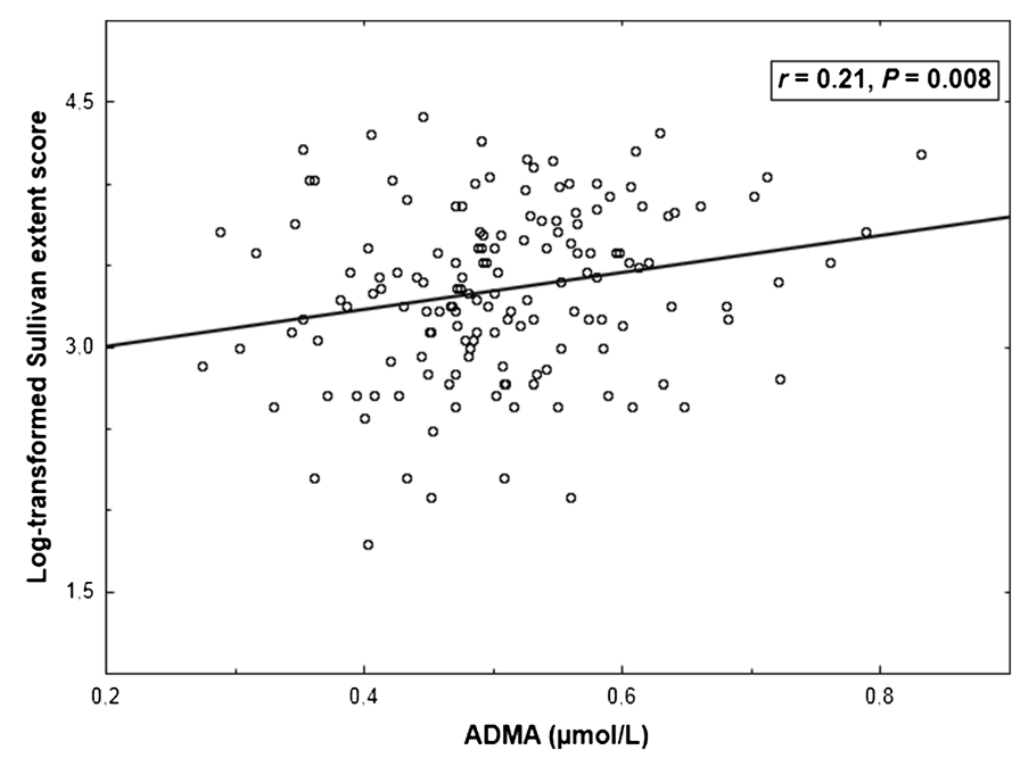

Figure $1 \mathrm{~A}$ positive correlation between plasma levels of asymmetric dimethylarginine (ADMA) and log-transformed Sullivan score of the extent of coronary atherosclerosis. $r$, Pearson's correlation coefficient.

multivariate approach in 997 patients with predominantly stable angina, which was yet limited to 638 nondiabetics. In 1,011 subjects undergoing elective coronary angiography, Wang et al. [9] reported elevated ADMA in the presence of $\geq 1$ coronary stenosis of $\geq 50 \%$ and/or history of myocardial infarction or coronary revascularization. However, those authors $[9,10]$ treated patients with a coronary diameter stenosis of $\geq 50 \%$ as a single group, whereas in the present study subjects with obstructive CAD were further discriminated according to the number of vessels involved and the Gensini and Sullivan scores.

On the other hand, in 1,364 patients, mainly nondiabetics with stable angina, Borgeraas et al. [14] recently reported even lower ADMA levels in subjects with significant $\mathrm{CAD}$, which is contradictory to our findings. Nevertheless, they also observed no relationship between ADMA and the presence of 3-vessel CAD [14], in accordance with our data. Finally, as Schnabel et al. [7] did not list any measure of angiographic CAD among covariates associated with ADMA in 1,874 CAD patients from the AtheroGene study, it can possibly be suspected that those correlations were statistically insignificant. Similarly, Siegerink et al. [52] have not presented data on the relationship between angiographic variables and ADMA in 1,148 subjects with stable CAD participating in the KAROLA ("Langzeitfolge der KARdiOLogischen Anschlussheilbehandlung") study.

Therefore, our findings suggest of a link between ADMA and diffuse, not focal, coronary atherosclerosis. As most acute coronary syndromes occur due to plaque rupture with superimposed occlusive thrombosis at sites involving non-obstructive coronary narrowings [53-56], this concept might explain significant independent associations of ADMA with adverse outcome but not with indices of CAD severity (the presence of angiographically obstructive CAD [9] or Friesinger score [8]) upon multivariate adjustment for traditional risk factors, renal function and C-reactive protein in the previously cited reports on patients referred to coronary angiography $[8,9]$. In keeping with this hypothesis, Bigi et al. [57] demonstrated that an angiographic extent score provided an additional prognostic information beyond the number of coronary lesions of $\geq 70 \%$ in 228 stable CAD subjects over a mean follow-up of 30 months. Furthermore, an association of elevated ADMA with the risk of myocardial infarction was found even by Borgeraas et al. [14] despite lower ADMA levels in subjects with significant CAD as mentioned previously.

\section{Insulin resistance versus angiographic CAD}

The lack of correlation between HOMA-IR and angiographic $\mathrm{CAD}$ is contradictory to reports on a positive relationship between angiographic CAD extent and IR assessed by the insulin suppression test or HOMA-IR which was observed in small groups $(n=38-83)$ of non-diabetic subjects with stable CAD $[23,24,26]$. Additionally, we have previously found that the magnitude of integrated insulin response to an oral glucose tolerance test, a surrogate measure of IR [58], was related to multivessel $\mathrm{CAD}$ in 52 non-diabetic men below 50 years of age, which was absent in older subjects [59].

On the other hand, Vonbank et al. [28] observed no difference in HOMA-IR between subgroups of 986 
consecutive patients undergoing elective coronary angiography divided according to the presence or number of lumen narrowings of $\geq 50 \%$, irrespective of diabetes status. Accordingly, that the lack of a positive association between angiographic CAD and HOMA-IR was also reported in an adequately powered study [28], strengthens our negative findings. It is noteworthy that a negative result had been previously described in 797 men by Solymoss et al. [22] who related the number of coronary arteries with $\geq 50 \%$ stenosis to fasting insulinemia, a surrogate marker of IR. Although An et al. [29] identified HOMA-IR as an independent predictor of one-year coronary atherosclerosis progression in 366 CAD subjects, however, Gensini score at baseline did not correlate to HOMA-IR, in agreement with our results.

Nevertheless, a recent meta-analysis involving over 500,000 subjects without diabetes, mainly without prevalent atherosclerotic $\mathrm{CV}$ disease at baseline, proved the ability of HOMA-IR to predict incident $\mathrm{CV}$ events with a $46 \%$ increase in the relative risk of symptomatic CAD per 1-SD increment in HOMA-IR [19]. This was consistent with the independent association of HOMA-IR and CV mortality in 5,511 nondiabetic, adult participants of the third U.S. National Health and Nutrition Examination Survey (NHANES III) during a mean follow-up of 8.5 years [18]. Furthermore, Tenenbaum et al. [17] confirmed an independent adverse prognostic effect of HOMAIR in 2,938 patients with preexisting CAD over a mean follow-up of 6.2 years. However, it is noteworthy that in 5,464 participants of Multi-Ethnic Study of Atherosclerosis (MESA) free of prevalent atherosclerotic $\mathrm{CV}$ disease the prognostic effect of HOMA-IR on the incidence and progression of coronary artery calcification over a 1.6-3.2-year follow-up disappeared after adjustment upon the components of the metabolic syndrome, lying downstream of IR [60].

Accordingly, it was hypothesized that the detrimental prognostic value of HOMA-IR in non-diabetic CAD patients even after controlling for the presence of the metabolic syndrome [61] or its traits $[17,62]$ might rather be attributable to the precipitation of acute CV events than to the slow progression of coronary atherosclerosis [28]. In addition, a role of IR in the development of restenosis after coronary stenting has also been suggested [63,64]. Therefore, this concept is analogous to the previously proposed hypothesis suggestive of the mechanisms other than ADMA being a correlate of more severe coronary atherosclerosis as an explanation of the well-recognized ability of ADMA to predict adverse outcome in CAD [7-10,14].

\section{Insulin resistance in relation to the L-arginine-NO- ADMA pathway}

In our hands, HOMA-IR and ADMA were independent of each other, confirming an earlier analysis in a subgroup of the study patients [43]. Stühlinger et al. [31] were the first to report a positive association between ADMA levels and the magnitude of IR in hypertensive and normotensive subjects, which precipitated the notion of ADMA as a common contributor to IR and endothelial dysfunction [65], an antecedent of coronary plaques $[66,67]$. In that seminal study IR was quantified as a steady-state plasma glucose concentration during simultaneous infusions of insulin, glucose and a somatostatin analogue, i.e., insulin suppression test [31]. Intriguingly, in spite of experimental evidence supporting mechanistic links between ADMA and IR within the liver and the skeletal muscle [68], the majority of clinical studies - except for Marliss et al. [34] - revealed no relationship of ADMA and the insulin-mediated glucose uptake during a hyperinsulinemic euglycemic clamp $[30,35,69,70]$, the golden standard method for IR assessment. Additionally, inconsistent results were obtained when IR was represented by HOMA-IR or a steady-state plasma glucose during the insulin suppression test with either positive $[32,33,38,42]$ or lacking $[36,37,39]$ relations between IR and ADMA.

On the other hand, the magnitude of IR was linked to a polymorphism in the gene encoding one of isoforms of dimethylarginine dimathylaminohydrolase (DDAH-2) [40], an enzyme controlling the majority of ADMA catabolism [71]. In an animal study circulating ADMA, in contrast to endothelial function, was related to the activity of DDAH-1 but not DDAH-2 [72], the latter being predominant in the vascular endothelium [73]. Accordingly, the link between circulating ADMA and the degree of IR could be obscured by the inability of plasma ADMA to reflect its intracellular level in endothelial cells, which had previously been suggested by Maas et al. [74] as an explanation for the lack of correlation between plasma ADMA and polymorphisms in the promoter region of the DDAH-2 gene that were related to the prevalence of hypertension.

Irrespective of mutual relations between ADMA and IR, their differential associations with the generation and/or bioavailability of NO, an endogenous antiatherogenic molecule, appear relevant in terms of atherogenesis. Accordingly, that in our patients angiographic CAD extent was correlated to ADMA, but not IR, is compatible with the recent report by Tessari et al. [75] who demonstrated that ADMA but not IR was a negative modulator of wholebody NO generation in subjects with atherosclerotic risk factors. Admittedly, previous studies suggested a coupling of insulin metabolic sensitivity to insulin's vascular effects and endothelial function [76-78]. However, although 
insulin-induced vasodilation is NO-dependent [76], there is also evidence supporting the dissociation between, on the one side, insulin's ability to stimulate glucose uptake, and, on the other side, insulin's vasodilatory action as well as NO formation or bioavailability both at baseline and under hyperinsulinemic conditions [30,79-81]. That Natali et al. [82] recently observed a deterioration in glucose tolerance but no changes in the magnitude of peripheral IR on acute inhibition of NO synthesis in non-diabetic subjects, is also consistent with the notion of IR-independent effects of NO deficiency.

Finally, in addition to the putative ability of ADMA to impair NO generation, other potential mechanisms of proatherogenic ADMA activity were recently suggested, such as an association of ADMA with increased arterial stiffness described in prediabetic subjects [83] and patients on maintenance hemodialysis [84]. Although peripheral blood pressure was similar in our CAD subjects and controls, however, elevated central arterial pressure in the presence of higher ADMA could have contributed to coronary atherosclerosis.

\section{Study limitations}

First, the number of participants was relatively small and the number of subjects in the control group was over 4fold lower compared to the CAD group. Nevertheless, we applied a wide set of exclusion criteria in order to restrict the sources of interindividual variability within our study groups. Second, ADMA levels can be influenced by medications, especially ACE inhibitors [85] and possibly some statins [73]. However, the ability of this effect to interfere with the associations of ADMA with angiographic CAD was probably limited because we had included exclusively patients who were receiving ACE inhibitors and statins for $\geq 3$ months prior to blood withdrawal for ADMA assay. Third, the magnitude of IR was estimated by HOMA, whereas a hyperinsulinemic euglycemic clamp is the golden standard for IR quantification. Furthermore, Reaven [86] recently raised concerns with regard to using HOMA-IR as a measure of IR when altered insulin clearance considerably affects changes in fasting insulinaemia, which was shown on acute NO formation blockade [82]. This limitation constrains conclusions based on HOMA-IR in our previous study [43] and also the present one, all the more because interindividual differences in ADMA could influence NO bioavailability [87]. Nonetheless, for feasibility reasons, we were not able to perform the clamps in a series of CAD patients referred to diagnostic coronary angiography.

\section{Conclusions}

In summary, ADMA levels appear to reflect diffuse but not focal coronary atherosclerosis in non-diabetic men with stable CAD irrespective of the magnitude of impaired metabolic sensitivity to insulin. Hence, the independent association between ADMA and coronary atherosclerotic burden may contribute to the well-recognized prognostic effect of ADMA in CAD.

\section{Abbreviations}

ACE: Angiotensin-converting enzyme; ADMA: Asymmetric dimethylarginine; CAD: Coronary artery disease; CV: Cardiovascular; DDAH: Dimethylarginine dimethylaminohydrolase; eGFR: Estimated glomerular filtration rate;

HDL: High-density lipoproteins; HOMA-IR: Homeostasis model assessment for insulin resistance; IR: Insulin resistance; NO: Nitric oxide.

\section{Competing interests}

The authors declare that they have no competing interests.

\section{Authors' contributions}

OK conceived and designed the study, collected and analyzed data, and wrote the manuscript. AS and AG contributed to the study design, data analysis and discussion, and supervised the study. All authors read, critically revised and approved the final manuscript.

\section{Acknowledgements}

This work was supported in part by a research grant (No. K/ZDS/003761) from the Ministry of Science and Higher Education, Warsaw, Poland. The funding body had no role in study design, the collection, analysis, and interpretation of data, the writing of the manuscript, and the decision to submit the manuscript for publication.

\section{Author details}

${ }^{1}$ Department of Coronary Artery Disease, The John Paul II Hospital, 80 Prądnicka Street, Cracow 31-202, Poland. ${ }^{2} 2$ nd Department of Cardiology, Jagiellonian University Medical College and University Hospital, 17 Kopernika Street, Cracow 31-501, Poland. ${ }^{3}$ Division of Therapeutic Education for Chronic Diseases, Geneva University Hospitals, 24 rue Micheli-du Crest, 1211-Geneva-14, Switzerland.

Received: 5 August 2013 Accepted: 7 October 2013 Published: 9 October 2013

\section{References}

1. Böger RH, Maas R, Schulze F, Schwedhelm E: Asymmetric dimethylarginine (ADMA) as a prospective marker of cardiovascular disease and mortality-an update on patient populations with a wide range of cardiovascular risk. Pharmacol Res 2009, 60:481-487.

2. Jacobi J, Maas R, Cardounel AJ, Arend M, Pope AJ, Cordasic N, HeusingerRibeiro J, Atzler D, Strobel J, Schwedhelm E, Böger RH, Hilgers KF: Dimethylarginine dimethylaminohydrolase overexpression ameliorates atherosclerosis in apolipoprotein E-deficient mice by lowering asymmetric dimethylarginine. Am J Pathol 2010, 176:2559-2570.

3. Miyazaki H, Matsuoka H, Cooke JP, Usui M, Ueda S, Okuda S, Imaizumi T: Endogenous nitric oxide synthase inhibitor: a novel marker of atherosclerosis. Circulation 1999, 99:1141-1146.

4. Furuki K, Adachi H, Matsuoka H, Enomoto M, Satoh A, Hino A, Hirai Y, Imaizumi T: Plasma levels of asymmetric dimethylarginine (ADMA) are related to intima-media thickness of the carotid artery: an epidemiological study. Atherosclerosis 2007, 191:206-210.

5. Maas R, Xanthakis V, Polak JF, Schwedhelm E, Sullivan LM, Benndorf R, Schulze F, Vasan RS, Wolf PA, Böger RH, Seshadri S: Association of the endogenous nitric oxide synthase inhibitor ADMA with carotid artery intimal media thickness in the Framingham Heart Study offspring cohort. Stroke 2009, 40:2715-2719.

6. Zoccali C, Bode-Böger S, Mallamaci F, Benedetto F, Tripepi G, Malatino L, Cataliotti A, Bellanuova I, Fermo I, Frölich J, Böger R: Plasma concentration of asymmetrical dimethylarginine and mortality in patients with endstage renal disease: a prospective study. Lancet 2001, 358:2113-2117.

7. Schnabel R, Blankenberg S, Lubos E, Lackner KJ, Rupprecht HJ, EspinolaKlein C, Jachmann N, Post F, Peetz D, Bickel C, Cambien F, Tiret L, Münzel T: Asymmetric dimethylarginine and the risk of cardiovascular events and 
death in patients with coronary artery disease: results from the AtheroGene Study. Circ Res 2005, 97:e53-e59.

8. Meinitzer A, Seelhorst U, Wellnitz B, Halwachs-Baumann G, Boehm BO, Winkelmann BR, März W: Asymmetrical dimethylarginine independently predicts total and cardiovascular mortality in individuals with angiographic coronary artery disease (the Ludwigshafen Risk and Cardiovascular Health study). Clin Chem 2007, 53:273-283.

9. Wang Z, Tang WH, Cho L, Brennan DM, Hazen SL: Targeted metabolomic evaluation of arginine methylation and cardiovascular risks: potential mechanisms beyond nitric oxide synthase inhibition. Arterioscler Thromb Vasc Biol 2009, 29:1383-1391

10. Lu TM, Chung MY, Lin MW, Hsu CP, Lin SJ: Plasma asymmetric dimethylarginine predicts death and major adverse cardiovascular events in individuals referred for coronary angiography. Int J Cardio 2011, 153:135-140

11. Lu TM, Ding YA, Charng MJ, Lin SJ: Asymmetrical dimethylarginine: a novel risk factor for coronary artery disease. Clin Cardiol 2003, 26:458-464.

12. Schulze F, Lenzen H, Hanefeld C, Bartling A, Osterziel KJ, Goudeva L, Schmidt-Lucke C, Kusus M, Maas R, Schwedhelm E, Strödter D, Simon BC, Mügge A, Daniel WG, Tillmanns H, Maisch B, Streichert T, Böger $\mathrm{RH}$ : Asymmetric dimethylarginine is an independent risk factor for coronary heart disease: results from the multicenter Coronary Artery Risk Determination investigating the Influence of ADMA Concentration (CARDIAC) study. Am Heart J 2006, 152:493.e1-493.e8.

13. Thum T, Tsikas D, Stein S, Schultheiss M, Eigenthaler M, Anker SD, PooleWilson PA, Ertl G, Bauersachs J: Suppression of endothelial progenitor cells in human coronary artery disease by the endogenous nitric oxide synthase inhibitor asymmetric dimethylarginine. J Am Coll Cardiol 2005, 46:1693-1701

14. Borgeraas H, Strand E, Ringdal Pedersen E, Dierkes J, Ueland PM, Seifert R, Wilberg ER, Bohov P, Berge RK, Nilsen DW, Nygård O: Omega-3 status and the relationship between plasma asymmetric dimethylarginine and risk of myocardial infarction in patients with suspected coronary artery disease. Cardiol Res Pract 2012, 2012:201742.

15. Després JP, Lamarche B, Mauriège $P$, Cantin B, Dagenais GR, Moorjani $S$, Lupien PJ: Hyperinsulinemia as an independent risk factor for ischemic heart disease. N Engl J Med 1996, 334:952-957.

16. Yip J, Facchini FS, Reaven GM: Resistance to insulin-mediated glucose disposal as a predictor of cardiovascular disease. J Clin Endocrinol Metab 1998, 83:2773-2776

17. Tenenbaum A, Adler $Y$, Boyko V, Tenenbaum H, Fisman EZ, Tanne D, Lapidot M, Schwammenthal E, Feinberg MS, Matas Z, Motro M, Behar S: Insulin resistance is associated with increased risk of major cardiovascular events in patients with preexisting coronary artery disease. Am Heart J 2007, 153:559-565.

18. Ausk KJ, Boyko EJ, loannou GN: Insulin resistance predicts mortality in nondiabetic individuals in the U.S. Diabetes Care 2010, 33:1179-1185.

19. Gast KB, Tjeerdema N, Stijnen T, Smit JW, Dekkers OM: Insulin resistance and risk of incident cardiovascular events in adults without diabetes: meta-analysis. PLoS One 2012, 72:e52036.

20. Eddy D, Schlessinger $L$, Kahn R, Peskin B, Schiebinger R: Relationship of insulin resistance and related metabolic variables to coronary artery disease: a mathematical analysis. Diabetes Care 2009, 32:361-366

21. Negri M, Sheiban I, Arigliano PL, Tonni S, Montresor G, Carlini S, Manzato F: Interrelation between angiographic severity of coronary artery disease and plasma levels of insulin, C-peptide and plasminogen activator inhibitor-1. Am J Cardiol 1993, 72:397-401.

22. Solymoss BC, Marcil M, Chaour M, Gilfix BM, Poitras AM, Campeau L: Fasting hyperinsulinism, insulin resistance syndrome, and coronary artery disease in men and women. Am J Cardiol 1995, 76:1152-1156.

23. Shinozaki K, Suzuki M, Ikebuchi M, Hara Y, Harano Y: Demonstration of insulin resistance in coronary artery disease documented with angiography. Diabetes Care 1996, 19:1-7.

24. Takezako T, Saku K, Zhang B, Shirai K, Arakawa K: Insulin resistance and angiographical characteristics of coronary atherosclerosis. Jpn Circ J 1999, 63:666-673.

25. Kwon K, Choi D, Koo BK, Ryu SK: Decreased insulin sensitivity is associated with the extent of coronary artery disease in patients with angina. Diabetes Obes Metab 2005, 7:579-585.
26. Granér M, Syvänne M, Kahri J, Nieminen MS, Taskinen MR: Insulin resistance as predictor of the angiographic severity and extent of coronary artery disease. Ann Med 2007, 39:137-144.

27. Anuurad E, Tracy RP, Pearson TA, Kim K, Berglund L: Synergistic role of inflammation and insulin resistance as coronary artery disease risk factors in African Americans and Caucasians. Atherosclerosis 2009. 205:290-295.

28. Vonbank A, Saely CH, Rein P, Beer S, Breuss J, Boehnel C, Drexel H: Insulin resistance is associated with the metabolic syndrome and is not directly linked to coronary artery disease. Clin Chim Acta 2011, 412:1003-1007.

29. An X, Yu D, Zhang R, Zhu J, Du R, Shi Y, Xiong X: Insulin resistance predicts progression of de novo atherosclerotic plaques in patients with coronary heart disease: a one-year follow-up study. Cardiovasc Diabetol 2012, 11:71.

30. Surdacki A, Nowicki M, Sandmann J, Tsikas D, Böger RH, Bode-Böger SM, Kruszelnicka-Kwiatkowska O, Kokot F, Dubiel JS, Frölich JC: Reduced urinary excretion of nitric oxide metabolites and increased plasma levels of asymmetric dimethylarginine in men with essential hypertension. J Cardiovasc Pharmacol 1999, 33:652-658.

31. Stühlinger MC, Abbasi F, Chu JW, Lamendola C, McLaughlin TL, Cooke JP, Reaven GM, Tsao PS: Relationship between insulin resistance and an endogenous nitric oxide synthase inhibitor. JAMA 2002, 287:1420-1426.

32. Eid HM, Eritsland J, Larsen J, Arnesen H, Seljeflot I: Increased levels of asymmetric dimethylarginine in populations at risk for atherosclerotic disease. Effects of pravastatin. Atherosclerosis 2003, 166:279-284.

33. McLaughlin T, Stühlinger M, Lamendola C, Abbasi F, Bialek J, Reaven GM, Tsao PS: Plasma asymmetric dimethylarginine concentrations are elevated in obese insulin-resistant women and fall with weight loss. J Clin Endocrinol Metab 2006, 91:1896-1900.

34. Marliss EB, Chevalier S, Gougeon R, Morais JA, Lamarche M, Adegoke OA, Wu G: Elevations of plasma methylarginines in obesity and ageing are related to insulin sensitivity and rates of protein turnover. Diabetologia 2006, 49:351-359.

35. Surdacki A, Stochmal E, Szurkowska M, Bode-Böger SM, MartensLobenhoffer J, Stochmal A, Klecha A, Kawecka-Jaszcz K, Dubiel JS, Huszno B, Szybiński Z: Nontraditional atherosclerotic risk factors and extent of coronary atherosclerosis in patients with combined impaired fasting glucose and impaired glucose tolerance. Metabolism 2007, 56:77-86.

36. Zsuga J, Torok J, Magyar MT, Valikovics A, Gesztelyi R, Lenkei A, Csiba L, Kéki $\mathrm{S}$, Zsuga M, Bereczki D: Dimethylarginines at the crossroad of insulin resistance and atherosclerosis. Metabolism 2007, 56:394-399.

37. Schutte AE, Schutte R, Huisman HW, van Rooyen JM, Fourie CM, Malan L, Malan NT, Schwedhelm E, Strimbeanu S, Anderssohn M, Böger RH: Dimethylarginines: their vascular and metabolic roles in Africans and Caucasians. Eur J Endocrinol 2010, 162:525-533.

38. Perticone F, Sciacqua A, Maio R, Perticone M, Galiano Leone G, Bruni R, Di Cello S, Pascale A, Talarico G, Greco L, Andreozzi F, Sesti G: Endothelial dysfunction, ADMA and insulin resistance in essential hypertension. Int J Cardiol 2010, 142:236-241.

39. Lu TM, Lin SJ, Lin MW, Hsu CP, Chung MY: The association of dimethylarginine dimethylaminohydrolase 1 gene polymorphism with type 2 diabetes: a cohort study. Cardiovasc Diabetol 2011, 10:16.

40. Andreozzi F, Presta I, Mannino GC, Scarpelli D, Di Silvestre S, Di Pietro N, Succurro E, Sciacqua A, Pandolfi A, Consoli A, Hribal ML, Perticone F, Sesti G: A functional variant of the dimethylarginine dimethylaminohydrolase-2 gene is associated with insulin sensitivity. PLoS One 2012, 7:e36224.

41. Işıklar OO, Barutcuoğlu B, Kabaroğlu C, Mutaf I, Özmen D, Bayındır O, Zoghi $\mathrm{M}$, Uluer H: Do cardiac risk factors affect the homocysteine and asymmetric dimethylarginine relationship in patients with coronary artery diseases? Clin Biochem 2012, 45:1325-1330.

42. Dimitroulas T, Sandoo A, Veldhuijzen van Zanten JJ, Smith JP, Hodson J, Metsios GS, Stavropoulos-Kalinoglou A, Kitas GD: Predictors of asymmetric dimethylarginine levels in patients with rheumatoid arthritis: the role of insulin resistance. Scand J Rheumatol 2013, 42:176-181.

43. Surdacki A, Kruszelnicka O, Rakowski T, Jażwińska-Kozuba A, Dubiel JS: Asymmetric dimethylarginine predicts decline of glucose tolerance in men with stable coronary artery disease: a 4.5 -year follow-up study. Cardiovasc Diabetol 2013, 12:64

44. Levey AS, Greene T, Kusek J, Beck G: A simplified equation to predict glomerular filtration rate from serum creatinine. J Am Soc Nephrol 2000, 11:155A. 
45. Surdacki A, Marewicz E, Wieteska E, Szastak G, Rakowski T, WieczorekSurdacka E, Dudek D, Pryjma J, Dubiel JS: Association between endothelial progenitor cell depletion in blood and mild-to-moderate renal insufficiency in stable angina. Nephrol Dial Transplant 2008, 23:2265-2273.

46. Matthews DR, Hosker JP, Rudenski AS, Naylor BA, Treacher DF, Turner RC: Homeostatic model assessment: insulin resistance and $\beta$-cell function from fasting plasma glucose and insulin concentrations in man. Diabetologia 1985, 28:412-419.

47. Schulze F, Wesemann R, Schwedhelm E, Sydow K, Albsmeier J, Cooke JP, Böger RH: Determination of asymmetric dimethylarginine (ADMA) using a novel ELISA assay. Clin Chem Lab Med 2004, 42:1377-1383.

48. Ringqvist I, Fisher LD, Mock M, Davis KB, Wedel H, Chaitman BR, Passamani E, Russell RO Jr, Alderman EL, Kouchoukas NT, Kaiser GC, Ryan TJ, Killip T, Fray D: Prognostic value of angiographic indices of coronary artery disease from the Coronary Artery Surgery Study (CASS). J Clin Invest 1983, 71:1854-1866.

49. Sullivan DR, Marwick TH, Freedman SB: A new method of scoring coronary angiograms to reflect extent of coronary atherosclerosis and improve correlation with major risk factors. Am Heart J 1990, 119:1262-1267.

50. Gensini GG: A more meaningful scoring system for determining the severity of coronary heart disease. Am J Cardiol 1983, 51:606.

51. Neeland IJ, Patel RS, Eshtehardi P, Dhawan S, McDaniel MC, Rab ST, Vaccarino V, Zafari AM, Samady H, Quyyumi AA: Coronary angiographic scoring systems: an evaluation of their equivalence and validity. Am Heart J 2012, 164:547-552.e1.

52. Siegerink B, Maas R, Vossen CY, Schwedhelm E, Koenig W, Böger R, Rothenbacher D, Brenner H, Breitling LP: Asymmetric and symmetric dimethylarginine and risk of secondary cardiovascular disease events and mortality in patients with stable coronary heart disease: the KAROLA follow-up study. Clin Res Cardiol 2013, 102:193-202.

53. Ambrose JA, Tannenbaum MA, Alexopoulos D, Hjemdahl-Monsen CE, Leavy J, Weiss M, Borrico S, Gorlin R, Fuster V: Angiographic progression of coronary artery disease and the development of myocardial infarction. J Am Coll Cardiol 1988, 12:56-62.

54. Little WC, Constantinescu M, Applegate RJ, Kutcher MA, Burrows MT, Kahl FR, Santamore WP: Can coronary angiography predict the site of a subsequent myocardial infarction in patients with mild-to-moderate coronary artery disease? Circulation 1988, 78(5 Pt 1):1157-1166.

55. Tousoulis D, Davies G, Crake T, Lefroy DC, Rosen S, Maseri A: Angiographic characteristics of infarct-related and non-infarct-related stenoses in patients in whom stable angina progressed to acute myocardial infarction. Am Heart J 1998, 136:382-388.

56. Yamagishi M, Terashima M, Awano K, Kijima M, Nakatani S, Daikoku S, Ito K, Yasumura Y, Miyatake K: Morphology of vulnerable coronary plaque: insights from follow-up of patients examined by intravascular ultrasound before an acute coronary syndrome. J Am Coll Cardiol 2000, 35:106-111.

57. Bigi R, Cortigiani L, Colombo P, Desideri A, Bax JJ, Parodi O: Prognostic and clinical correlates of angiographically diffuse non-obstructive coronary lesions. Heart 2003, 89:1009-1013.

58. Yeni-Komshian H, Carantoni M, Abbasi F, Reaven GM: Relationship between several surrogate estimates of insulin resistance and quantification of insulin-mediated glucose disposal in 490 healthy nondiabetic volunteers. Diabetes Care 2000, 23:171-175.

59. Kruszelnicka-Kwiatkowska O, Surdacki A, Goldsztajn P, Matysek J, Piwowarska W, Golay A: Relationship between hyperinsulinemia and angiographically defined coronary atherosclerosis in non-diabetic men. Diabetes Metab 2002, 28(4 Pt 1):305-309.

60. Blaha MJ, DeFilippis AP, Rivera JJ, Budoff MJ, Blankstein R, Agatston A, Szklo M, Lakoski SG, Bertoni AG, Kronmal RA, Blumenthal RS, Nasir K: The relationship between insulin resistance and incidence and progression of coronary artery calcification: the Multi-Ethnic Study of Atherosclerosis (MESA). Diabetes Care 2011, 34:749-751.

61. Saely $\mathrm{CH}$, Aczel S, Marte $T$, Langer $P$, Hoefle $G$, Drexel $H$ : The metabolic syndrome, insulin resistance, and cardiovascular risk in diabetic and nondiabetic patients. J Clin Endocrinol Metab 2005, 90:5698-5703.

62. Yanase M, Takatsu F, Tagawa T, Kato T, Arai K, Koyasu M, Horibe H, Nomoto S, Takemoto K, Shimizu S, Watarai M: Insulin resistance and fasting hyperinsulinemia are risk factors for new cardiovascular events in patients with prior coronary artery disease and normal glucose tolerance. Circ J 2004, 68:47-52.
63. Sekiguchi M, Kurabayashi M, Adachi H, Hoshizaki H, Oshima S, Taniguchi K: Usefulness of insulin resistance measured by homeostasis model assessment in predicting restenosis after coronary stent placement in nondiabetic patients. Am J Cardiol 2004, 93:920-922

64. Nishio K, Fukui T, Tsunoda F, Kawamura K, Itoh S, Konno N, Ozawa K, Katagiri T: Insulin resistance as a predictor for restenosis after coronary stenting. Int J Cardiol 2005, 103:128-134.

65. Sydow K, Mondon CE, Cooke JP: Insulin resistance: potential role of the endogenous nitric oxide synthase inhibitor ADMA. Vasc Med 2005, 10 (Suppl 1):S35-S43.

66. Al Suwaidi J, Hamasaki S, Higano ST, Nishimura RA, Holmes DR Jr, Lerman A: Long-term follow-up of patients with mild coronary artery disease and endothelial dysfunction. Circulation 2000, 101:948-954.

67. Schächinger V, Britten MB, Zeiher AM: Prognostic impact of coronary vasodilator dysfunction on adverse long-term outcome of coronary heart disease. Circulation 2000, 101:1899-1906.

68. Sydow K, Mondon CE, Schrader J, Konishi H, Cooke JP: Dimethylarginine dimethylaminohydrolase overexpression enhances insulin sensitivity. Arterioscler Thromb Vasc Biol 2008, 28:692-697.

69. Eid HM, Reims H, Arnesen H, Kjeldsen SE, Lyberg T, Seljeflot I: Decreased levels of asymmetric dimethylarginine during acute hyperinsulinemia. Metabolism 2007, 56:464-469.

70. Marcovecchio ML, Widmer B, Dunger DB, Dalton RN: Effect of acute variations of insulin and glucose on plasma concentrations of asymmetric dimethylarginine in young people with type 1 diabetes. Clin Sci 2008, 115:361-369.

71. Achan V, Broadhead M, Malaki M, Whitley G, Leiper J, MacAllister R, Vallance $P$ : Asymmetric dimethylarginine causes hypertension and cardiac dysfunction in humans and is actively metabolized by dimethylarginine dimethylaminohydrolase. Arterioscler Thromb Vasc Biol 2003, 23:1455-1459.

72. Wang D, Gill PS, Chabrashvili T, Onozato ML, Raggio J, Mendonca M, Dennehy K, Li M, Modlinger P, Leiper J, Vallance P, Adler O, Leone A, Tojo A, Welch WJ, Wilcox CS: Isoform-specific regulation by $N^{G}, N^{G}$ dimethylarginine dimethylaminohydrolase of rat serum asymmetric dimethylarginine and vascular endothelium-derived relaxing factor/NO. Circ Res 2007, 101:627-635

73. Surdacki A: L-arginine analogs - inactive markers or active agents in atherogenesis? Cardiovasc Hematol Agents Med Chem 2008, 6:302-311.

74. Maas R, Erdmann J, Lüneburg N, Stritzke J, Schwedhelm E, Meisinger C, Peters A, Weil J, Schunkert H, Böger RH, Lieb W: Polymorphisms in the promoter region of the dimethylarginine dimethylaminohydrolase 2 gene are associated with prevalence of hypertension. Pharmacol Res 2009, 60:488-493.

75. Tessari P, Cecchet D, Artusi C, Vettore M, Millioni R, Plebani M, Puricelli L, Vedovato M: Roles of insulin, age, and asymmetric dimethylarginine, on nitric oxide synthesis in vivo. Diabetes 2013, 62:2699-2708.

76. Baron AD, Steinberg $H O$, Chaker $H$, Leaming R, Johnson A, Brechtel G: Insulin-mediated skeletal muscle vasodilation contributes to both insulin sensitivity and responsiveness in lean humans. J Clin Invest 1995, 96:786-792

77. Petrie JR, Ueda S, Webb DJ, Elliott HL, Connell JM: Endothelial nitric oxide production and insulin sensitivity. A physiological link with implications for pathogenesis of cardiovascular disease. Circulation 1996, 93:1331-1333.

78. Cleland SJ, Petrie JR, Small M, Elliott HL, Connell JM: Insulin action is associated with endothelial function in hypertension and type 2 diabetes. Hypertension 2000, 35(1 Pt 2):507-511.

79. Utriainen T, Mäkimattila S, Virkamäki A, Bergholm R, Yki-Järvinen H: Dissociation between insulin sensitivity of glucose uptake and endothelial function in normal subjects. Diabetologia 1996, 39:1477-1482.

80. Avogaro A, Piarulli F, Valerio A, Miola M, Calveri M, Pavan P, Vicini P, Cobelli C, Tiengo A, Calò L, Del Prato S: Forearm nitric oxide balance, vascular relaxation, and glucose metabolism in NIDDM patients. Diabetes 1997 46:1040-1046.

81. Surdacki A, Nowicki M, Sandmann J, Tsikas D, Kruszelnicka-Kwiatkowska O, Kokot F, Dubiel JS, Frölich JC: Effects of acute euglycemic hyperinsulinemia on urinary nitrite/nitrate excretion and plasma endothelin-1 levels in men with essential hypertension and normotensive controls. Metabolism 1999, 48:887-891.

82. Natali A, Ribeiro R, Baldi S, Tulipani A, Rossi M, Venturi E, Mari A, Macedo MP, Ferrannini E: Systemic inhibition of nitric oxide synthesis in non-diabetic 
individuals produces a significant deterioration in glucose tolerance by increasing insulin clearance and inhibiting insulin secretion. Diabetologia 2013, 56:1183-1191.

83. Protopsaltis I, Foussas S, Angelidi A, Gritzapis A, Sergentanis TN, Matsagos S, Tzirogiannis K, Panoutsopoulos Gl, Dimitriadis G, Raptis S, Melidonis A: Impact of ADMA, endothelial progenitor cells and traditional cardiovascular risk factors on pulse wave velocity among prediabetic individuals. Cardiovasc Diabetol 2012, 11:141

84. Zapolski T, Wysokiński A, Książek A, Jaroszyński A: Left atrial volume index and aortic stiffness index in adult hemodialysed patients-link between compliance and pressure mediated by endothelium dysfunction; a cross-sectional study. BMC Cardiovasc Disord 2012, 12:100.

85. Delles C, Schneider MP, John S, Gekle M, Schmieder RE: Angiotensin converting enzyme inhibition and angiotensin II AT1-receptor blockade reduce the levels of asymmetrical $N^{G}, N^{G}$-dimethylarginine in human essential hypertension. Am J Hypertens 2002, 15:590-593.

86. Reaven GM: What do we learn from measurements of HOMA-IR? Diabetologia 2013, 56:1867-1868.

87. Kruszelnicka O: Nitric oxide vs insulin secretion, action and clearance. Diabetologia. doi: 10.1007/s00125-013-3082-y. in press.

doi:10.1186/1475-2840-12-145

Cite this article as: Kruszelnicka et al:: Differential associations of angiographic extent and severity of coronary artery disease with asymmetric dimethylarginine but not insulin resistance in non-diabetic men with stable angina: a cross-sectional study. Cardiovascular Diabetology 2013 12:145.

\section{Submit your next manuscript to BioMed Central and take full advantage of:}

- Convenient online submission

- Thorough peer review

- No space constraints or color figure charges

- Immediate publication on acceptance

- Inclusion in PubMed, CAS, Scopus and Google Scholar

- Research which is freely available for redistribution 